Article

\title{
Identifying Users' Requirements for Emergency Mapping Team Operations in Small Island Developing States: Caribbean Perspective
}

\author{
Gregorio Rosario Michel 1,2,3,*®), Fernando Manzano Aybar ${ }^{2}\left(\mathbb{D}\right.$, Leris Neris Guzmán ${ }^{2}$, Christian Villalta Calderón ${ }^{4}$, \\ Teodoro Jiménez Durán ${ }^{3}{ }^{-1}$ and Joep Crompvoets ${ }^{1}$ (D)
}

Citation: Rosario Michel, G.; Manzano Aybar, F.; Neris Guzmán, L.; Villalta Calderón, C.; Durán, T.J.; Crompvoets, J. Identifying Users' Requirements for Emergency Mapping Team Operations in Small Island Developing States: Caribbean Perspective. ISPRS Int. J. Geo-Inf. 2021, 10, 307. https://doi.org/ 10.3390/ijgi10050307

Academic Editors: Biswajeet Pradhan and Wolfgang Kainz

Received: 24 February 2021

Accepted: 1 May 2021

Published: 6 May 2021

Publisher's Note: MDPI stays neutral with regard to jurisdictional claims in published maps and institutional affiliations.

Copyright: (c) 2021 by the authors. Licensee MDPI, Basel, Switzerland. This article is an open access article distributed under the terms and conditions of the Creative Commons Attribution (CC BY) license (https:/ / creativecommons.org/licenses/by/ $4.0 /)$.
1 Public Governance Institute (PGI), KU Leuven, 3000 Leuven, Belgium; joep.crompvoets@kuleuven.be

2 Departamento de Tecnología de la Información y Comunicación, Servicio Geológico Nacional de la República Dominicana (SGN), Santo Domingo 10148, Dominican Republic; fmanzano@unapec.edu.do (F.M.A.); leris.neris@minerd.gob.do (L.N.G.)

3 Escuela de Agrimensura, Universidad Nacional Pedro Henríquez Ureña (UNPHU), Santo Domingo 10602, Dominican Republic; tj5867@unphu.edu.do

4 Department of Civil Engineering, Environmental Engineering and Land Surveying, Polytechnic University of Puerto Rico (PUPR), San Juan 00918, Puerto Rico; cvillalta@pupr.edu

* Correspondence: gmichel12@uasd.edu.do; Tel.: +1-829-591-5360
Abstract: Small Island Developing States (SIDS) increasingly face natural hazards that overwhelm their capacity to generate and share spatial-information to reduce human-economic losses. Under such circumstances, the emergency mapping team (EMT) enables a common operational picture of the impacted communities. This paper aims to identify user requirements for EMT operations in the Caribbean and, based on those findings, improve the level of preparedness to deliver informationservices that contribute to disaster risk management in the region. The results are built upon a case-study and a survey targeted for technical personnel responsible for emergency mapping in three Caribbean states: the Dominican Republic, Saint Lucia and Sint Maarten. Our findings revealed five user requirements for EMT operations: institutional arrangements, implementation of a Cloud-based spatial data infrastructure, linking community stakeholders, partnerships and capacity building. This study provides the foundation for future EMT developments in the Caribbean region and in others SIDS with similar settings in the world.

Keywords: emergency mapping team; users' requirements; disaster risk management; geospatial information management; small island developing states

\section{Introduction}

\subsection{General Introduction}

Each year, the Small Island Developing States (SIDS) face potential challenges in achieving sustainable development, especially due to their social and economic characteristics and vulnerability to natural and human-made disasters (United Nations 2014). Herein, SIDS future annual losses related to natural disasters will represent almost 20 per cent of their total social expenditure [1].

The Caribbean is one of the most disaster-prone regions in the world. Just in the last 10 years, Caribbean SIDS have been impacted by 139 natural disasters [2]. The 2017 hurricanes Irma and Maria, as well as the 2010 magnitude 7.0 earthquake in Haiti, are clear examples of how disasters heavily affected the well-being and economic development of the Caribbean countries $[3,4]$.

In this context, researchers and practitioners have widely recognized the crucial role of geospatial information to enhance information-based decision-making during natural disasters [5-7]. However, Caribbean SIDS present major setbacks when attempts are made to share and access necessary information for disaster risk management (DRM) 
actions [8]. With such time and resource limitations, government agency capabilities might be constrained for the generation and sharing of geospatial resources for disaster risk managers $[8,9]$.

In response to disaster events, emergency mapping teams (EMT) have emerged as a solution for improving the performance of government agencies to meet the huge demand for spatial information and services in a short period of time $[8,10]$. The EMT focuses on supporting decision-makers on the definition and sharing of a common operational picture (COP) regarding the status of the impacted communities [11-13]. The COP is described as a single dissemination of critical information regarding the status of damages and disaster response activities, thus enabling effective decision-making, coordination, and integration between emergency response organizations $[9,10]$.

Despite the significant support that can bring EMT operations to the different stakeholders in charge of DRM, there is a serious gap on the identification of what and how to prepare beforehand for a timely and efficient integration between the government task-force and the EMT in Caribbean SIDS.

The central problem, as defined for our paper, thus reads: "What are the users' requirements for EMT operations in Caribbean SIDS?" In regard to this central problem, we shall deal with the following questions in this paper: who are the key users involved in EMT operations, and what are their users' requirements for EMT operations in Caribbean SIDS?

Previous research has shown interest in the study of user requirements in the field of spatial information and services for DRM activities. For example, Menold et al. [14] studied end-user requirements for generating a smartphone application to enhance communication during emergency response in the U.S.A. Another study in this field by Leitinger et al. [15] focuses on user requirements for a mobile disaster documentation system in the Alpine regions. Neuvel et al. [16] reported on a network-centric approach to identify relevant geoinformation and geotechnology for risk and emergency management in The Netherlands. Diehl and van der Heide [5] identified critical factors to establish a geoinformation facility to support the public order and safety sector. A more recent study by Rosario et al. [12] provided a good comprehensive analysis of EMT operations in the Dominican Republic (DR). Accordingly, standardization, establishment and maintenance of a spatial data infrastructure (SDI), as well as partnerships, effective communication among stakeholders and capacity building, are essential for EMT operations at the national level.

Although the aforementioned literature provides insight on user requirements of geospatial technologies for DRM, empirical research to date has been primarily on technological challenges in developed countries. In this sense, there is a paucity of research that analyzes social and technological user requirements in developing country settings-in particular, SIDS at the Caribbean region.

This research focuses on the identification of users' requirements for EMT operations in Caribbean SIDS. The contribution of this work will serve as a basis for a deeper theoretical understanding and for deriving sound and practical solutions for improving EMT operations for effective DRM in the Caribbean region and in other parts of the world with similar settings.

The methodology used in this research relies on a case study of three Caribbean SIDS: the Dominican Republic, Saint Lucia and Sint Maarten. The results are built upon an online survey questionnaire that focused on each main task of the EMT operation workflow for disaster response in the selected countries. To our knowledge, user requirements for EMT operations in Caribbean SIDS have not been identified, analyzed and compared to each other before. The results contribute to a better understanding of what needs to be prepared in order to deliver information and services during future emergency mapping actions for DRM tasks.

The paper is structured in the following way. The remaining part of Section 1 introduces a theoretical overview, including basic concepts of emergency mapping team and user requirements identification, followed by the geographical settings of the study area in the Caribbean SIDS. Section 2 explains the methodology used in this research. Section 3 shows the survey 
results. Section 4 then presents a discussion of the survey results. Section 5 closes the paper with the main conclusions on the identification of user requirements for EMT operations in Caribbean SIDS.

\subsection{Literature Review}

This sub-section briefly introduces the key terms emergency mapping team and user requirements identification.

\subsubsection{Emergency Mapping Team}

The term Emergency Mapping Team (EMT) refers to a collaborative group of mapping specialists, often on a voluntary basis, to support decision-makers in defining and sharing a common operational picture regarding the status of damage and disaster response activities [9]. EMT operations are commonly focused on the creation and distribution of disaster-related maps (including reference, operational and statistical maps), sharing geospatial data generated during the response period and delivery of location- based services $[15,16]$. Figure 1 illustrates the general workflow for EMT operations.

(a) Gathering information and stakeholders' needs

(b) Generating data

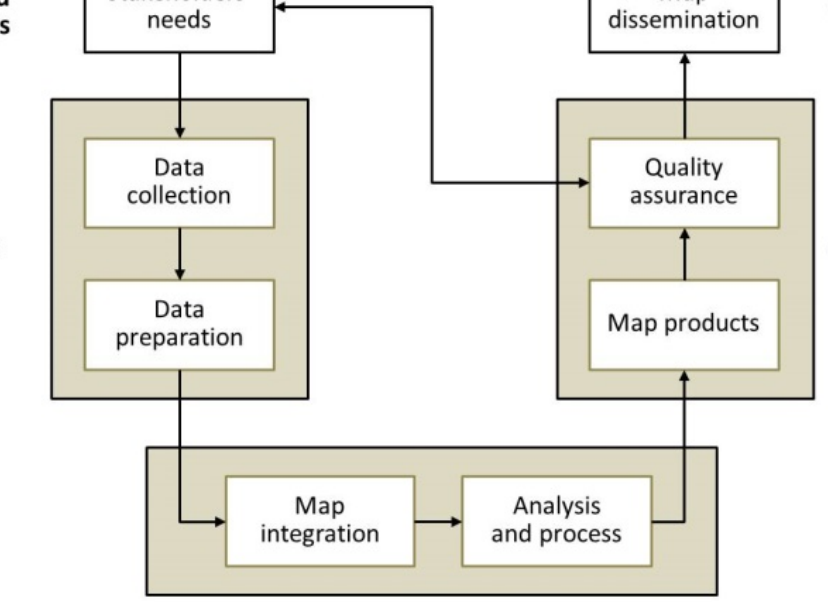

(e) Products sharing and continuous updates

(d) Mapping and layout

(c) Data and spatial processing

Figure 1. General workflow for EMT operations (adapted from [12]).

As shown in Figure 1, the EMT's work begins by gathering information about the needs and general affairs for generating and sharing a COP of the impacted communities. Then, it proceeds to collect, organize, analyze and process information from different sources. The process follows with the creation and sharing of map products and services to meet different stakeholders' applications, mainly emergency command centers, local governments and general public. As time progresses, the EMT continuously updates all geospatial resources to meet stakeholders' needs $[17,18]$.

\subsubsection{User Requirements}

User requirements (UR) refers to the features/attributes your product should have or how it should perform from the user's perspective [19]. User requirements are also perceived as high-level, abstract requirements based on end users' and other stakeholders' viewpoints [20]. In this study, UR mean a user's description of the functionality and performance characteristics of the proposed product [21]; herein, UR refer to the description 
of geospatial and non-geospatial information and services necessary for the EMT operations to achieve their goals.

\subsection{Geographical Settings of the Study Area: Caribbean SIDS}

This sub-section briefly presents the geographical setting of Caribbean SIDS, followed by a short profile of the Dominican Republic, Saint Lucia and Sint Maarten.

\subsubsection{Caribbean SIDS}

The Caribbean is home to $16 \mathrm{UN}$-member SIDS and 7 non-UN-member SIDS (UNOHRLLS 2011) (Figure 2). Together, these countries have a population of over 43 million inhabitants. In the Caribbean, more than half of the population lives within $1.5 \mathrm{~km}$ of the shoreline [22]. Caribbean SIDS in particular base most of their livelihoods on revenues from tourism [23].

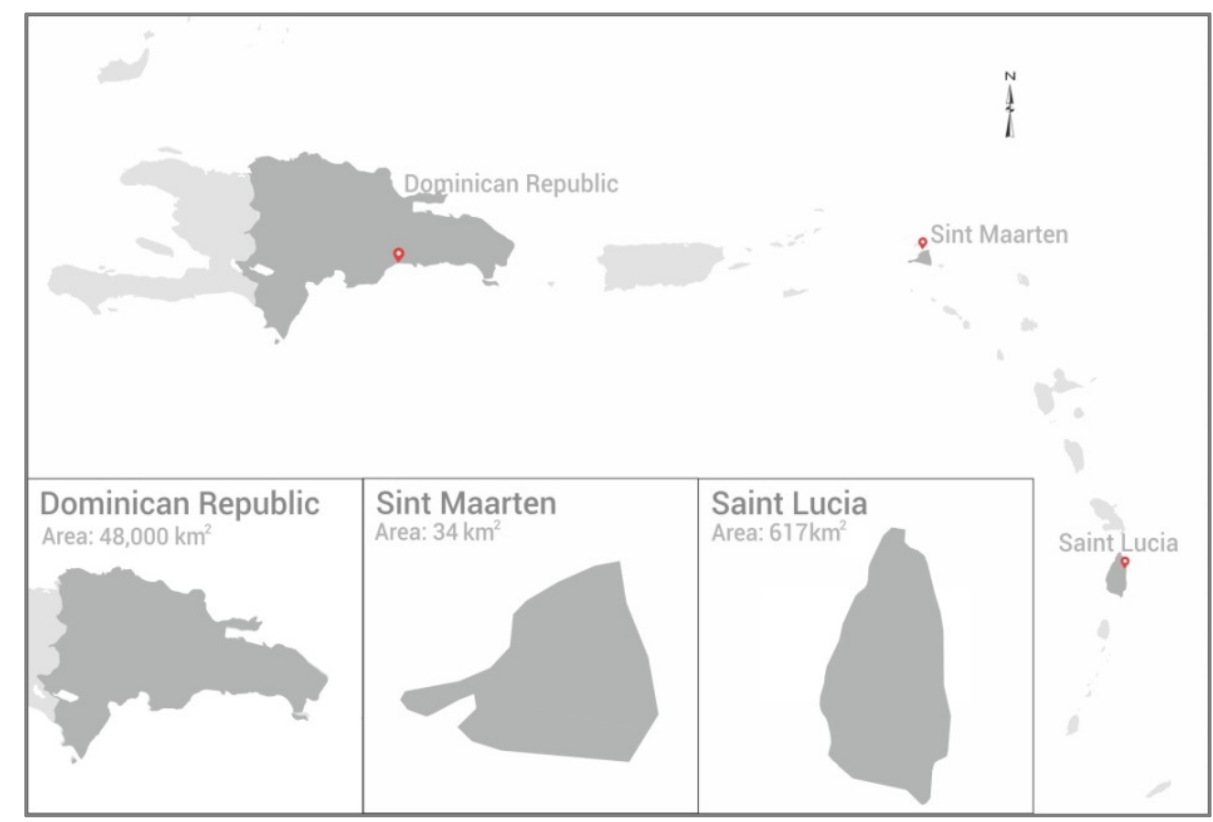

Figure 2. Location of selected countries: the Dominican Republic, St. Maarten and St. Lucia.

Caribbean countries are extremely vulnerable to climate change and natural disasters. The impact of hurricanes and floods alone in the region is approximately 2 percent of GDP per year [24]. For instance, in Sint Maarten alone, Hurricanes Irma and Maria (2017) caused an estimated physical damage of more than USD 1.18 billion [3].

In the Caribbean, institutional efforts toward regional disaster risk management are based on active outcomes from the Caribbean Disaster and Emergency Management Agency (CDEMA). CDEMA is a regional inter-governmental agency with the primary responsibility of the coordination of emergency response and relief efforts, as well as the promotion and engineering of a comprehensive disaster management approach in the Caribbean community [25].

\subsubsection{Dominican Republic}

The Dominican Republic (DR) is the second most populated state among SIDS, with 10.5 million inhabitants and more than 3.3 million citizens living in the capital city [26]. Hurricanes have the most severe impact in terms of lives lost in the Dominican Republic [27]. Major earthquakes and tsunamis are a constant threat to the DR, mainly due to the interaction of the North American tectonic plate with the Caribbean tectonic plate on which the island is located [28]. The Inter-Institutional Geospatial Information Team (EIGEO, in Spanish) is the government unit responsible for executing EMT operations in the DR. Map products generated by EIGEO are used by government officers who coordinate disaster 
response efforts in the National Emergency Operations Center. These maps are also shared among local response agencies via the National Integrated Information System (SINI, in Spanish), which is a tailored clearinghouse system for disaster response purposes [12].

\subsubsection{Saint Lucia}

Saint Lucia has a population of approximately 166,000 inhabitants, of which $72 \%$ lives in rural communities [29]. The country has an area of $620 \mathrm{~km}^{2}$, with an exclusive economic zone of about $15,484 \mathrm{~km}^{2}$ [30].

Hurricanes and landslides are the most common natural hazards [31]. From 2010 to 2016, there have been five major disasters in Saint Lucia, comprising two tropical cyclones, one drought, one flash flood and one riverine flood [2]. The National Emergency Management Organization (NEMO), jointly with the Department of Physical Planning, is responsible for emergency mapping activities in Saint Lucia.

\subsubsection{Sint Maarten}

Sint Maarten is located in the northeastern Caribbean Sea. The country population is estimated at around 37,224 inhabitants, living in a total area of $34 \mathrm{~km}^{2}$. The geographical location of St Maarten, which is part of the Lesser Antilles volcanic arc, means the island is subject to two major natural phenomena: tropical cyclones during the annual hurricane season, and earthquakes. Furthermore, it has a high level of seismicity and is prone to flash floods, cyclonic swell and tsunami [32]. The Ministry of Public Housing, Spatial Planning, Environment and Infrastructure (VROMI, in Dutch) is the key stakeholder for spatial planning and mapmaking for disaster management activities in Sint Maarten [33].

\section{Materials and Methods}

In this paper, we have aimed at identifying users' requirements for EMT operations in SIDS. Since this purpose seems to be too broad, an in-depth examination of this phenomenon has to be performed in a different context. Therefore, a case study method seems to be the most appropriate approach for this research. A case study method is described as an empirical inquiry that investigates a contemporary phenomenon within its real-life context, especially when the boundaries between the phenomenon and its context are not clearly evident [34].

In this research, a case study of three SDIS in the Caribbean region will be examined, in which the research as a whole cover the same research questions for each of the individual selected country. The unit of analysis for this case study is the EMT operations. The EMT is organized, trained, and equipped to perform the following tasks within general workflow for EMT operations: (a) gathering information and stakeholder needs; (b) generating data; (c) geospatial data processing; (d) mapping and layout; and (e) product sharing and continuous updates.

In order to identify user requirements for EMT operations in the selected countries, we applied a four-stage general methodology to analyze user requirements, as proposed by Maguire and Bevan [35]. Figure 3 presents the research stages followed in this study.

\subsection{Research Stages}

\subsubsection{Information Gathering}

At first, a semi-structured interview was conducted to define a list of potential users, stakeholders and information about processes that intervene in EMT operations. Interviews were targeted at senior professionals responsible for the coordination of emergency mapping tasks when there is a disaster. Interview outcomes were the basis for identifying a list of 29 key user respondents: the Dominican Republic (17), Saint Lucia (8) and Sint Maarten (4). During the second stage, a cross-sectional online survey was administered to identify EMT user needs in each of the three selected countries: theDominican Republic (August to September 2018), Sint Maarten and Saint Lucia (September to November, 2019). 


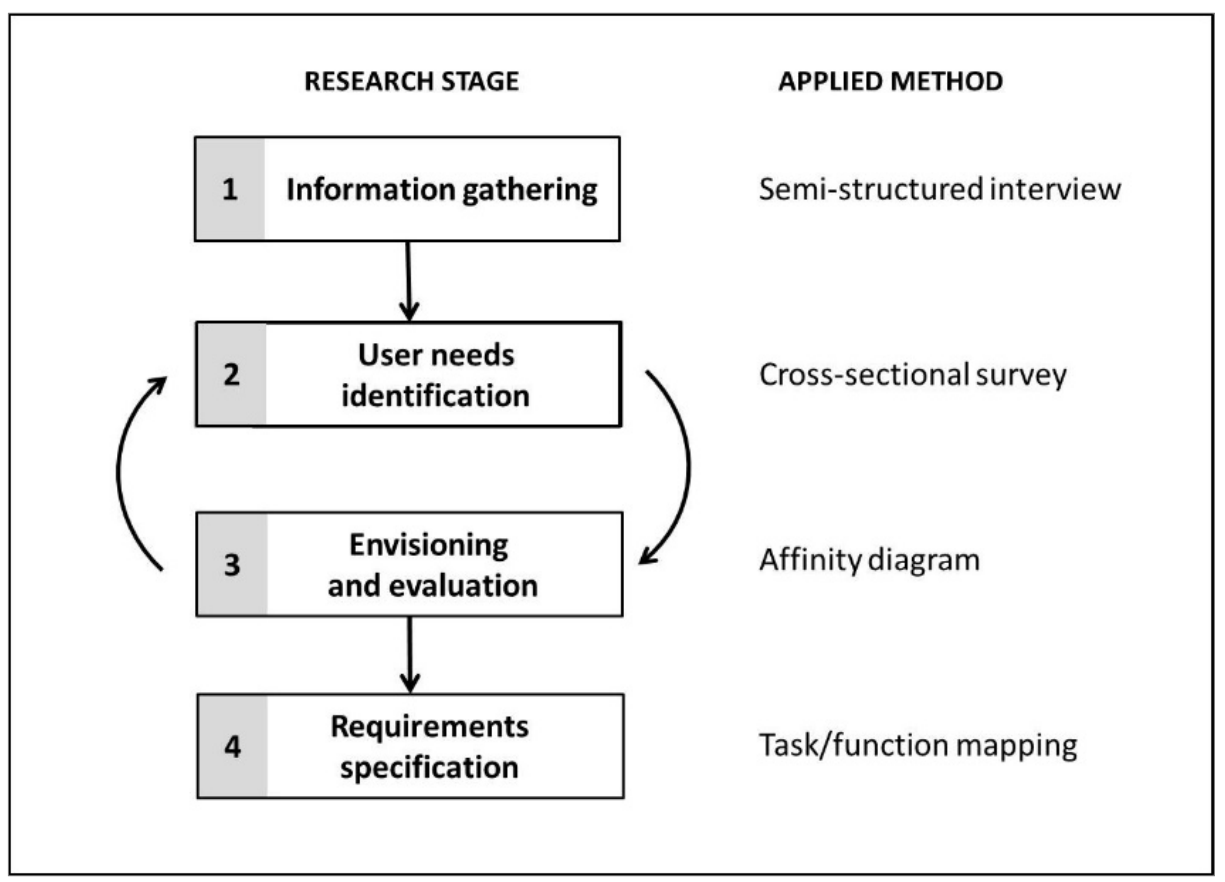

Figure 3. Research architecture to identify user requirements.

\subsubsection{User Needs Identification}

The questionnaire was designed to capture the respondents' insights on how to perform more effective EMT operations. The questionnaire consisted of 40 questions, including multiple-choice, close-ended, open-ended and four-point Likert scale questions. The questionnaire was divided into five sections. Each section was related to a main task of the general workflow for EMT operations [9].

The questionnaire also inquired about the type of organizational setting, capacity building program and stakeholder participation required for EMT operations. The questionnaire was pre-tested through interviews with experienced GIS professionals and EMT coordinators in each country for readability and clarity purposes. Technical and managerial personnel actively involved in EMT operations and processes were recruited to participate in the survey. The questionnaire link was sent, and responses were received via e-mail and an online web form to enable digital data collection from spatially distributed respondents. The survey was accessible at the following address: https:/ / forms.gle/2WTxH9ZiuPNUCmK3A (accessed on 24 September 2019). In order to increase the response rate, three reminder emails were sent, and field trips were taken to each country.

The final survey sample yielded 28 responses out of 33 EMT members; hence, a response rate of 85 percent was achieved. Collected data were tabulated and analyzed using SPSS software.

\subsubsection{Envisioning and Evaluation}

At the third stage, affinity diagram technique was used to identify and index issues and insight on EMT users' needs [36]. All data relevant to a particular task of the general workflow for EMT operations were grouped together to form categories. These categories were the basis for evaluating and specifying users' requirements for the different tasks that they perform.

\subsubsection{Requirements Specification}

At the last stage (Stage 4), a task/function mapping technique [35] was used to specify key minimum users' requirements that lead to successful EMT operations in the Caribbean SIDS context. 


\subsection{Cases Selection}

In this case study, the SIDS countries were selected on the basis of three criteria: (1) different level of geospatial infrastructure readiness, (2) previous experiences with emergency mapping operations, and (3) a variety of characteristics, including population and major natural hazards.

The Dominican Republic (DR) was selected because of its demographic characteristics, as it is the second most populated country among SIDS, with a high population concentration in urban areas. Since 2013, the DR has accumulated valuable experience, through the Inter-Institutional Geo-Spatial Information Team (EIGEO), while dealing with emergency mapping operations. Sint Maarten and Saint Lucia were selected because both islands have been widely hit by the latest severe hurricanes in the Caribbean region.

In particular, Saint Lucia is at the initial stage of strengthening their capabilities to respond to emergency mapping needs at the National Emergency Management Office (NEMO) and the Department of Physical Planning.

\subsection{Survey Population}

In this study, respondents were grouped by their country of origin (Q1): Dominican Republic (DR) (57\%), Saint Lucia (LC) (29\%) and Sint Maarten (SXM) (14\%). Up to 70\% of the respondents worked for government agencies, followed by a small representation from the military forces (7\%) (Q2). Respondents mostly worked for geomatics (39\%) and disaster risk management departments (25\%) (Q3).

Respondents were asked questions regarding their educational and professional experience in the field of emergency mapping. Bachelor's degree accounted for 39\% of survey respondents' qualification, followed by master's degree (36\%) and technician (25\%) (Q4). Respondents had professional expertise mostly in geographic information system (29\%) and disaster risk management (11\%) (Q5).

The respondents ranged in years of experience in emergency mapping from 1 year to 22 years with an average of 9 years (Q7). Respondents represented government agencies as auxiliary (46\%) or formal (43\%) members in EMT operations (Q8). Remaining respondents (11\%) were external EMT members. Mapping and layout (75\%), data collection (61\%), coordination and data analysis (each at about $46 \%$ ), were the main tasks executed for EMT operations (Q9) (Figure 4).

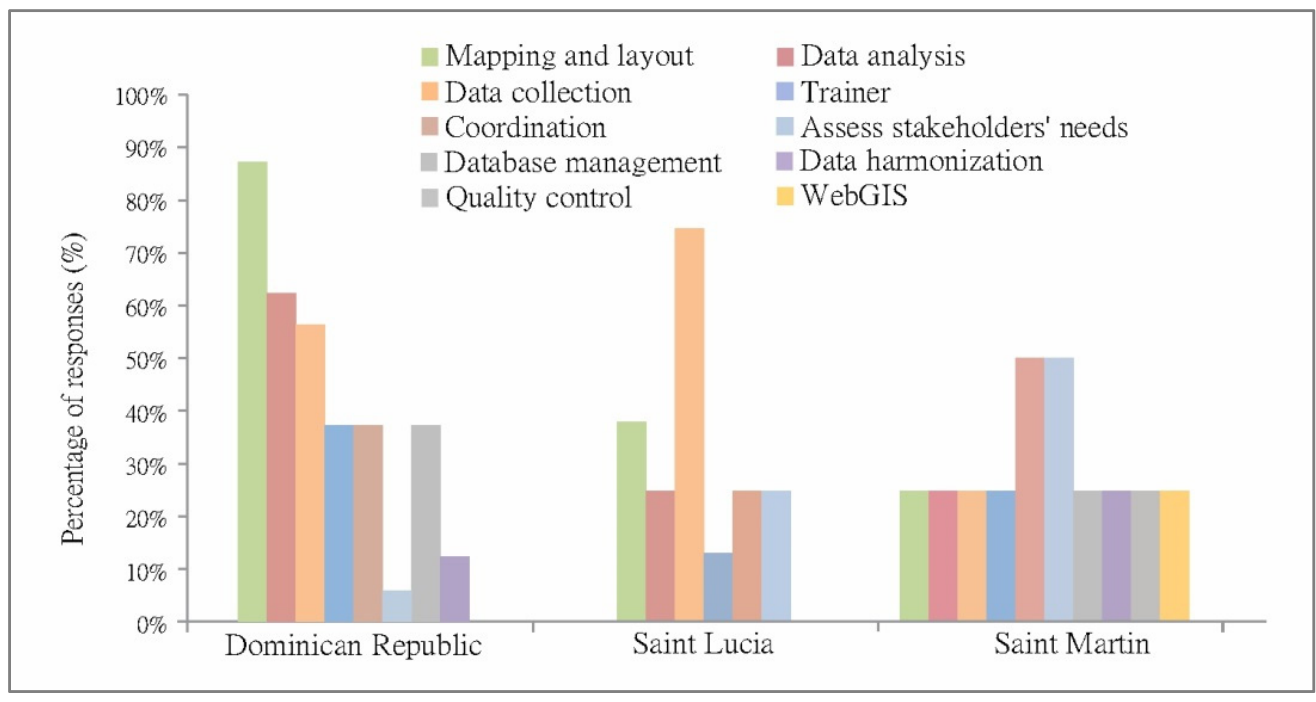

Figure 4. Distribution of responses by participants' tasks (Q9). 
At this point, survey results suggest that EMT structure and functions are similar across the selected countries, which are mainly led by the government agencies.

\section{Results}

\subsection{Gathering Information and Stakeholders' Needs}

In this section of the survey, respondents were asked questions regarding communication strategy and technologies used for capturing the stakeholders' demands of information and services. A four-point Likert scale question (ranging from never to always) was used to ask how frequently the respondents use a listed communication channels to gather information about the users' demands (Q10). More than half of the respondents (57\%) cited e-mails as the most used communication channel. A majority of respondents $(80 \%)$ are still relying on face-to-face meetings with stakeholders.

One survey question was asked to determine which missing stakeholders should be involved in EMT operations (Q11). Most of the respondents agreed that the universities, research institutes and drone owners should participate in EMT efforts (Figure 5).

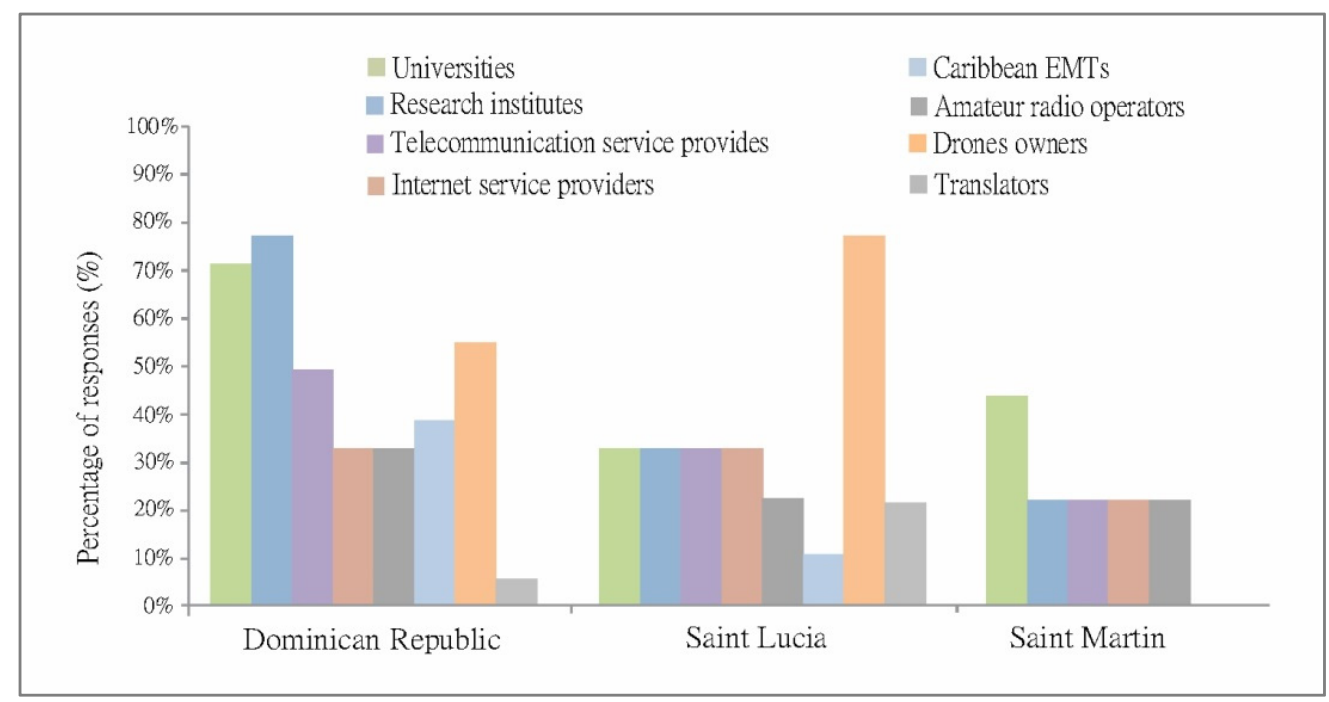

Figure 5. Missing stakeholders in EMT operations (Q11).

One open question asked the respondents to indicate the needs of stakeholders regarding necessary information gathering (Q12). Most of the respondents agreed on necessities about the standardization of data and metadata, tools for data collection and capacity building. In particular, LC respondents mentioned the need to improve the quality of base maps. DR and SXM respondents similarly suggested a necessary improvement in community support and timely communication with EMT stakeholders.

Respondents were openly asked to mention what information is needed for capturing EMT stakeholders' requirements (Q13). Having a clear idea of technical specification of the information and its purpose and a database of stakeholders' profiles were deemed crucial by most of the respondents. LC and SXM respondents similarly cited the necessity to create mechanisms to capture lessons learned and feedback from technical and strategic stakeholders, while DR respondents suggested clarifying the stakeholders' information workflow.

At the end of this Section 2.3, an open question was asked to determine what improvements should be implemented for anticipating EMT users' needs (Q14). The implementation of an effective communication channel among the stakeholders, including social network, workshops, and automation and standardization of data collection processes, were the most cited recommendations (Table A1 in Appendix A). DR and LC respondents reported similar necessities on technical training and coordination mechanisms. Specifically, SXM respondents suggested the definition of technical specifications of the spatial data. 


\subsection{Generating Data}

This section of the survey started by asking questions on the specifications of geospatial datasets, devices used for data collection and restrictions experienced while using EMT data. A four-point Likert scale question (ranging from never to always) asked the respondents how frequently they use listed core datasets in EMT operations (Q15). Up to $82 \%$ of the respondents indicated that they always or sometimes use satellite imagery, administrative division, geographic names and hydrography datasets. Alternatively, DR respondents $(81 \%)$ indicated that they always or sometimes use digital elevation models, census and transport network datasets. Only $75 \%$ of SXM respondents indicated transport network as sometimes or always used. However, more than $88 \%$ of LC respondents also ranked with a high frequency of use topography and cadaster datasets.

This survey also asked the respondents which devices they use to acquire necessary EMT data (Q16). Printers (89\%), GPS (82\%), plotters (64\%) and mobile phones $(61 \%)$ are frequently or always used across the selected countries. When respondents were asked which data formats they use for generating thematic data for EMT operations, most of them listed text files (79\%), excel files (75\%) and shapefiles (50\%) as main formats for storing spatial and non-spatial information (Q17).

A four-point Likert scale question (ranging from not relevant to extremely relevant) asked respondents which cartographic scales are relevant for generating EMT data and maps (Q18). A total of 80\% of DR respondents marked the use of scales below 1:50,000 as relevant or extremely relevant. Alternatively, more than half of LC and SXM respondents similarly ranked scales below 1:20,000 as relevant. This range of scales used might be expected due to the differences in territorial extent among studied countries.

With respect to metadata information, the respondents reported that the most commonly used metadata format for EMT operations are Excel files (50\%) (Q19). A few of the respondents $(25 \%)$ also mentioned that they do not save any metadata information. One question asked respondents which database systems are mainly used to store spatial data (Q22). Most respondents mentioned that they mainly managed spatial data using ArcGIS Geodatabase (57\%) and PostgreSQL (25\%). The results revealed that different sources of information are needed to create EMT maps and services (Q20), while Google Earth (89\%), Open Street Map (71\%), and first responders' data from the field (50\%) are reported as the ones most commonly used (Figure 6).

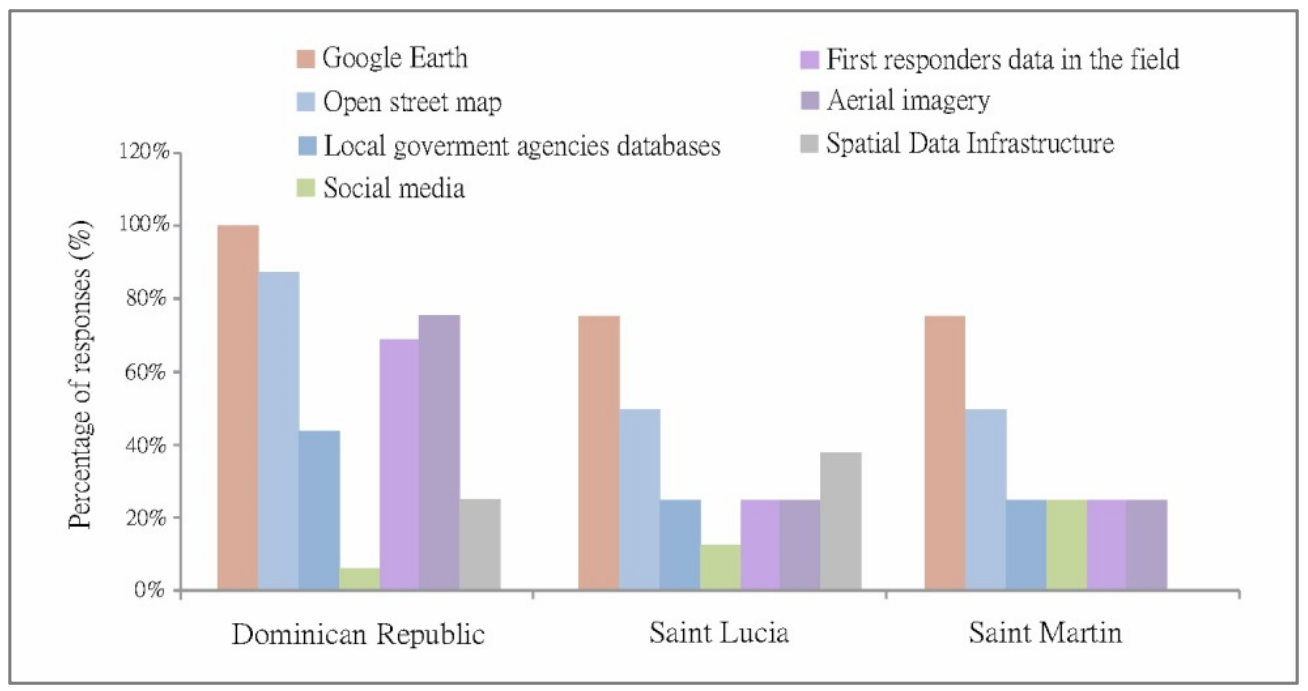

Figure 6. Utilization of data sources in EMT operations (Q20).

As part of this survey, the respondents were asked to suggest currently missing datasets for improving EMT operations $(\mathrm{Q} 23)$. The following disaster-related datasets were 
the ones most recommended by respondents (Figure 7): gas stations (64\%), shelters (61\%) and emergency operation facilities $(57 \%)$ datasets.

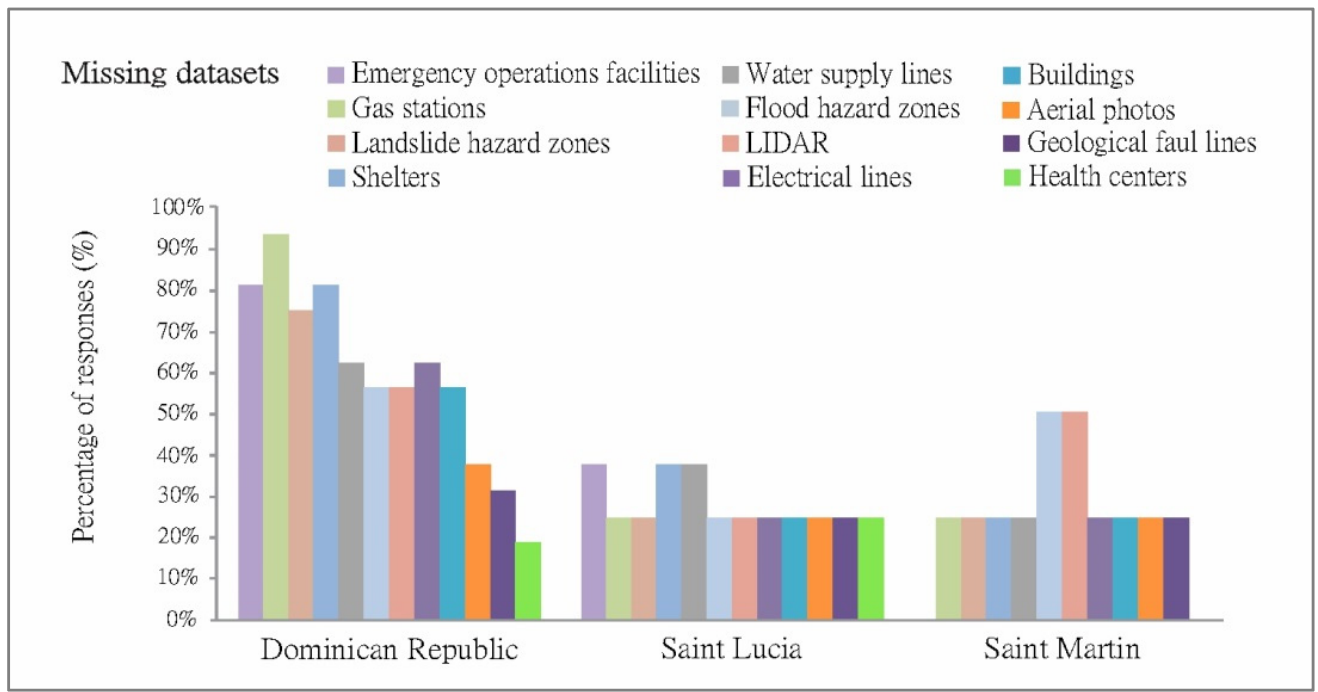

Figure 7. Missing datasets for improving the EMT operations (Q23).

One survey question asked respondents which restrictions they experienced while using data for EMT operations $(\mathrm{Q} 21)$. The restriction mentioned the most by respondents was the fact that EMT data cannot be shared with the public $(64 \%)$, while $24 \%$ of respondents also indicated that the data can be shared but just on a read-only capability (Figure 8). It was notable that SXM respondents reported the lowest level of restrictions using EMT data; nonetheless, they also reported the highest level of restrictions on data quality and availability.

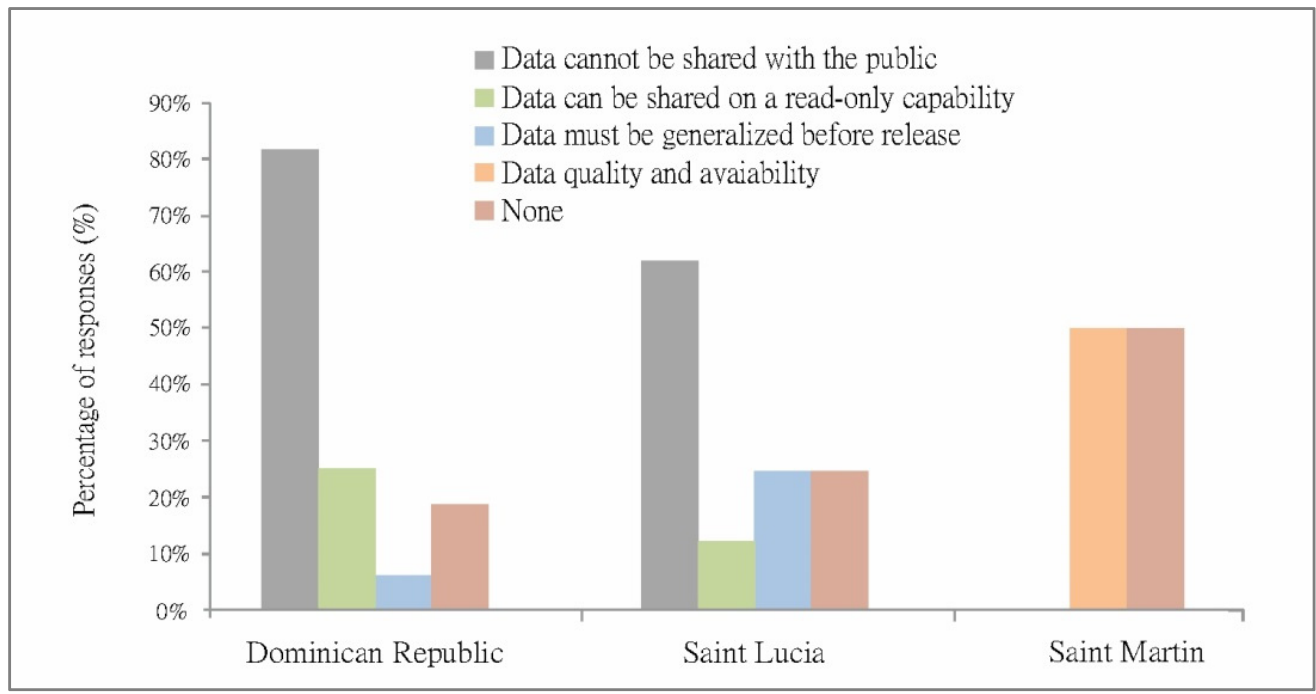

Figure 8. Restrictions using EMT data (Q21).

When the respondents were asked which tools they recommend to improve data gathering for EMT operations (Q24), the exploitation of satellite imagery $(82 \%)$ was the most recommended tool. The next most preferred tools were volunteered geographic information (VGI) technologies, SDI and 3D maps, each at about 75\%.

At the end of this Section 2.3, one open question asked the respondents to recommend improvements for data generation in EMT operations (Q25). Recommendations included a wide range of actions, mainly the following: implementation of a disaster- oriented 
SDI, training on data capture trends, and applications of mobile phones for real-time data collection from the field (Table A2 in Appendix A).

\subsection{Data and Geospatial Processing}

This section of the survey was intended to inquire about processing tasks in EMT operations, as well as the actions that should improve data and geospatial processing in the EMT workflow.

At first, the respondents were asked which tasks are relevant to integrate spatial data for EMT operations (Q26). Survey results showed that nearly $90 \%$ of respondents considered updating old data as a relevant or extremely relevant processing task in EMT operations (Figure 9). The second most frequent responses were completing missing features, conversion of data formats and georeferencing tasks, each at about $89 \%$.

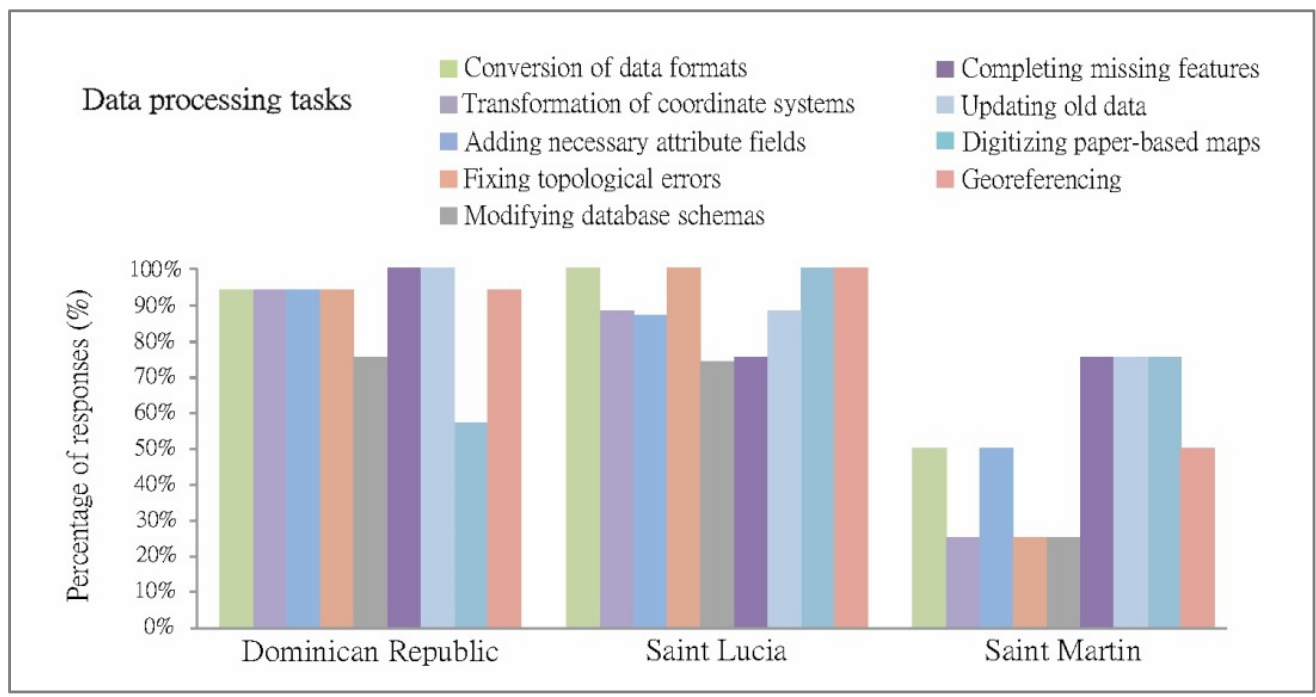

Figure 9. Data processing tasks in EMT operations (Q26).

One survey question asked the respondents to mention what software is frequently used to execute EMT operations (Q27). The majority of respondents replied that they frequently used ArcGIS (82\%), followed by QGIS software (68\%) for geospatial processing. Another survey question asked respondents to cite which hardware infrastructure is used to perform geospatial processing (Q28). Here, the analysis revealed that DR $(67 \%)$ and LC $(55 \%)$ respondents use stand-alone computers as hardware processing infrastructure, while SXM respondents reported more use of in-house local servers (50\%). The respondents were asked which media they use to store information resources (Q29). In general, respondents claimed that the information is mainly stored using local databases/servers $(79 \%)$, with a few respondents using cloud services (29\%).

At the end of this Section 2.3, one open question asked the respondents to recommend improvements for enhancing data and spatial processing in EMT operations (Q30). According to respondents' recommendations, the availability of distributed processing capabilities in the cloud, standardization of data and metadata and technical training on geospatial technologies and disaster risk management were the most frequent answers (Table A3 in Appendix A). Again, the respondents were also in favor of the implementation of a disaster-oriented SDI as an alternative to improve the workflow of EMT operations.

\subsection{Mapping and Layout}

In this section of the survey, questions were asked about the type and purpose of maps generated in EMT operations, as well as alternative solutions for enhancing this step of the mapmaking workflow. A four-point Likert scale question (ranging from never to always) was used to request respondents to indicate the maps they generated most frequently 
during EMT operations (Q31). The majority of respondents (71\%) similarly mentioned that critical infrastructure, roads and shelter maps were the maps generated most frequently (Q31) (Figure 10).

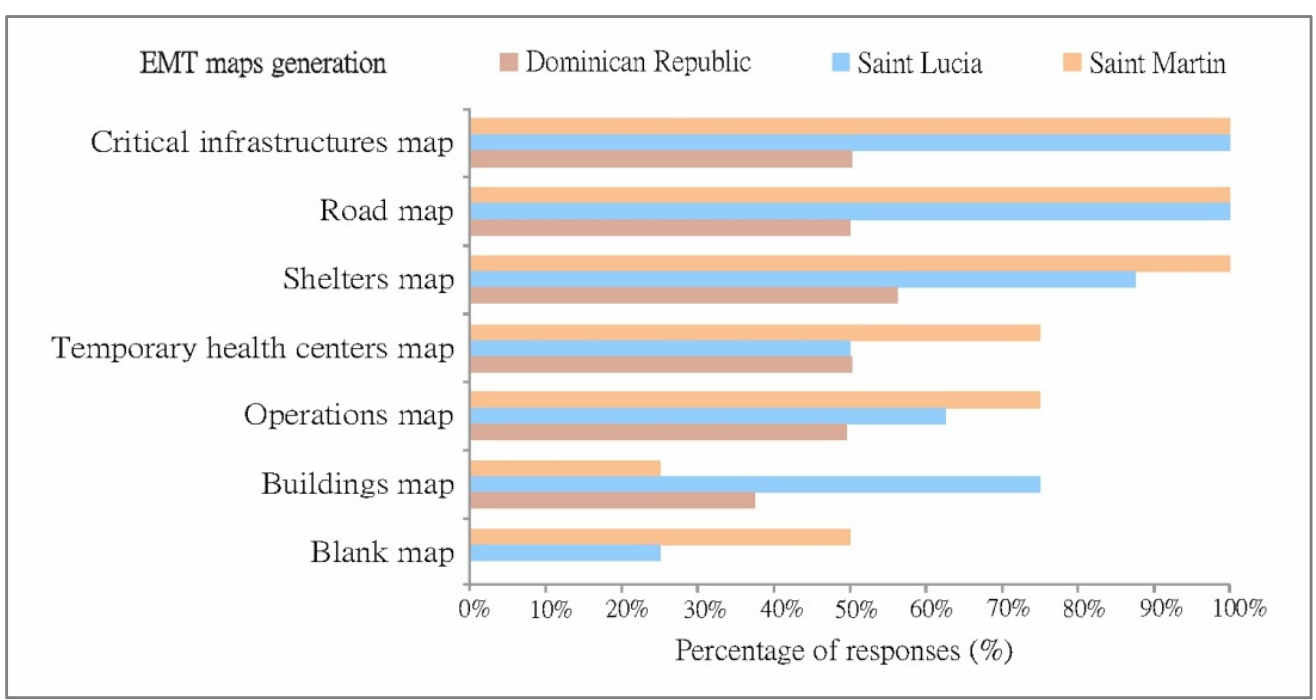

Figure 10. Type of maps generated in EMT operations (Q31).

One survey question asked the respondents to mention the main purposes of the maps generated for EMT operations (Q32). The results revealed that the EMT maps have a wide range of purposes, while the most frequent application was damage assessment $(82 \%)$, followed by risk assessment and emergency planning and preparedness, each at $79 \%$. In particular, it was notable that DR respondents ( $88 \%$ ) also cited support of emergency management stakeholders as the main purpose of EMT maps (Figure 11).

In response to an open question inquiring about recommendations for enhancing mapping and layout in EMT operations (Q33), the respondents mainly stated that technical capabilities for real-time data collection and sharing were necessary. Respondents were also in favor of non-technical actions, such as strengthening organizational and coordination capabilities of EMT stakeholders (Table A4 in Appendix A).

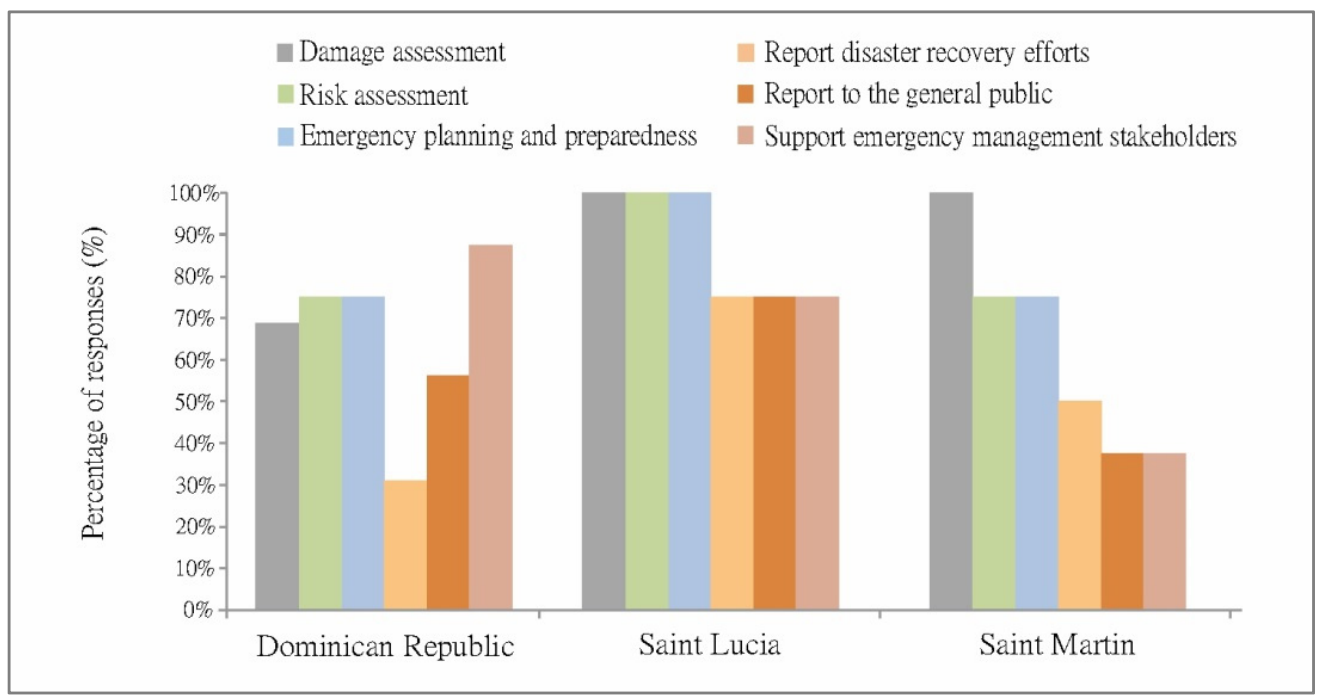

Figure 11. Main purposes of EMT maps (Q32). 


\subsection{Product Sharing and Continuous Updates}

This last section of the survey aimed to understand the delivery channels used for sharing EMT products. Here, the first question asked respondents which channels are currently offered for providing access to emergency maps and data products (Q34). Up to $50 \%$ of the respondents claimed to use geoportals and e-mails for providing access to EMT geospatial resources. Alternatively, one LC respondent (13\%) reported the continued use of file transfer protocol (FTP), while five DR respondents (12\%) indicated the use of SDI to provide access to EMT data.

A four-point Likert scale question (ranging from never to always) was used to request respondents to indicate the most frequently used media for sharing EMT products (Q35). The majority of respondents reported that they frequently or always used GIS maps (93\%) and digital images (83\%) (Figure 12). In particular, LC respondents reported the highest frequency for the use of paper maps $(88 \%)$.

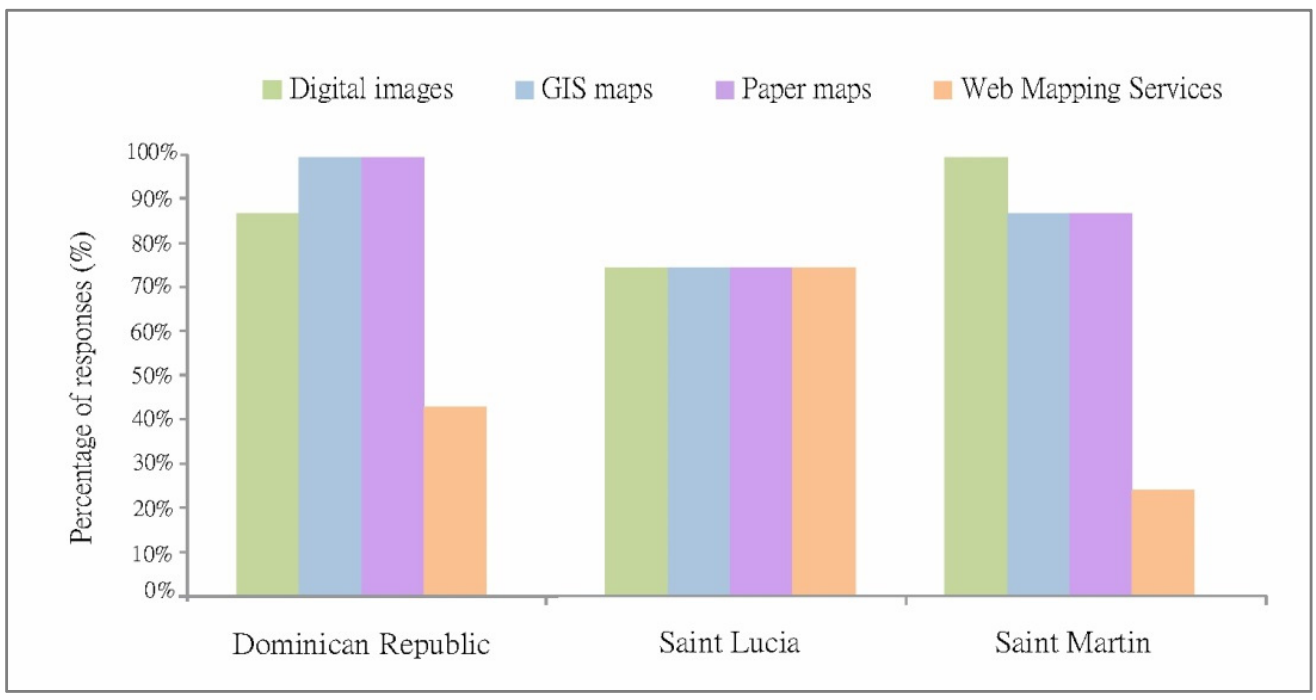

Figure 12. Main media for sharing EMT maps (Q35).

With regards to web service applications during EMT operations, a four-point Likert scale question (ranging from not relevant to extremely relevant) asked respondents to indicate the most relevant web services for improving efficiency in sharing EMT map products. Most of the respondents deemed web mapping services (WMS) as relevant or extremely relevant (82\%) for improving efficiency in map product sharing (Q36). DR and LC respondents similarly stated web coverage service (WCS) and web map tile service (WMTS as relevant for delivery of EMT products) each at about $75 \%$.

The respondents were also asked an open question to recommend improvements for products sharing and updating in EMT operations (Q37). The most recommended actions were the implementation of a SDI that opens spatial information to all stakeholders (Table A5 in Appendix A). Participatory mapping and capacity building were also mentioned as strong strategies to build relevant and up-to-date spatial information at the local level.

Regarding capacity building, a five-point Likert scale question (ranging from not important to very important) asked the respondents to rank the importance of a listed training courses to strengthen EMT operations (Q38). Specifically, all DR and SXM respondents ranked training on the use of GPS as fairly important or very important, followed by data collection techniques and big data, each at $75 \%$. All LC respondents were more in favor of geospatial database management and metadata trainings.

At the end of this study, one open question asked respondents to mention missing elements that had to be tackled in the questionnaire (Q39). Most of the respondents expressed their satisfaction with the experience of completing this survey. Specifically, two 
DR respondents suggested that internal bureaucratic procedures and the role of statistical tools and trainings to improve EMT operations were missing in this survey. One LC respondent believed that limitations related to human resources should be included in the study.

\section{Discussion}

The main goal of our study was to identify users' requirements for EMT operations in Caribbean SIDS. This research combined a case study method and a questionnaire survey to identify grounded arguments and a set of users' requirements for EMT operations in small island developing states.

Our results showed that EMT products and services have the potential to increase resilience and DRM effectiveness in SDIS, by providing quick access to relevant spatial information and maps for damage and risk assessment, and emergency planning and preparedness. This finding aligns with previous studies showing that effective information sharing among all stakeholders is essential for successful management of disasters [34-36].

Our findings suggested that direct communication with stakeholders using social networks and cloud-based platforms would be highly helpful to lead real-time coordination, communication and knowledge transfer for EMT operations in future DRM scenarios. In this regard, other authors similarly denoted social networks attributes in facilitating a two-way communication channel for knowledge sharing and reuse across all stakeholders in emergency circumstances $[4,6,37,38]$.

Regarding data generation for EMT operations, our results evidenced that significant attention is paid to the potential use of volunteered geographic information. This collaborative approach comprises the generation and sharing of user-generated geographic information to spatially enable local businesses, research institutes and relief organizations as key stakeholders for EMT operations in affected communities [39,40]. As stated by Haworth et al. [6] and Genovese and Stéphane [41], VGI presents opportunities to boost citizens' participation in the collaborative production of local knowledge for decision making. This VGI potential becomes more relevant when there is an urge for the most up-to-date information of unfolding events in the field.

In terms of data and geospatial processing, our findings revealed that the lack of standards and technical specifications for data and metadata capture, processing and sharing, constitutes a strong barrier for effective EMT operations in Caribbean SIDS. Ajmar et al. [17] and Rosario et al. [18] reported similar findings, stating that the enforcement of standards (cartographic workflow, symbology, map template, etc.) allows users to increase efficiency in emergency mapping operations.

Regarding technology infrastructure to build and share a common operational picture of the landscape, our results suggested that there is a great potential for the implementation of a cloud-based SDI tailored to EMT operations. Similarly, other authors recognized the significant contribution of cloud-based platforms as an effective method for capture, access, analysis, distribution and integration of data and map products in emergency response efforts [42]. However, basic electricity and internet services might be interrupted for days in the immediate aftermath of a humanitarian emergency; hence, these severe circumstances might prevent cloud-based platforms from being fully accessible for sharing and processing large quantities of data from the most vulnerable communities in the SIDS. Other authors also highlighted the lack of interoperability as one main drawback of using cloud computing, meaning that users must decide between flexibility and ease of use [43].

In terms of human resources, there was a strong consensus among the respondents regarding the necessity to increase capacity building initiatives to fill the gap and disparities of knowledge in terms of geospatial technologies and disaster risk management strategies. This may be explained by the limited number of skilled professionals involved in the integration of available technologies that have not been formally used for emergency mapping response [12]. In this sense, previous studies have also recognized capacity 
building as an influencing factor for information sharing and coordination in multiagency emergency response [44].

This research also showed that there is a strong interest in opening collaboration channels for exchanging information and resources with other non-traditional EMT stakeholders, including universities, research institutes and drone owners. Previous research shows that such a collaborative approach can be realized through institutional arrangements and partnerships that enable stakeholders to work together $([5,41,42]$. These instruments should ease and make possible the integration of externally developed spatial data solutions and knowledge into existing inter-organizational processes [43-46].

There are some limitations in our research approach. First, the limited number of countries studied might be considered a concern and a restriction for the applicability of the findings to a broader domain. Furthermore, potential stakeholders in EMT operations, such as research institutes, academia, private enterprises, NGOs and regional organizations are likely underrepresented in the study. However, the paucity of the existing literature on the region and the need for relevant information on the topic justify the approach. This research is likely relevant not only for developing states in the Caribbean region, but also for the other 52 SIDS in the world.

\section{Conclusions}

This research demonstrates the potential application of a user-centric approach to investigate user requirements for emergency mapping team operations in the real context of the SIDS in the Caribbean region. The identification and analysis of user requirements can be considered as a first step toward designing a roadmap for anticipating information and service needs for disaster preparation and response.

Despite the differences in the degree of maturity of the EMTs in the studied countries, our findings have revealed a set of five (5) essential user requirements that likely lead to practical implications for improving EMT operations in the Caribbean SIDS:

Requirement 1: Institutional arrangements. Currently, EMT users face major restrictions for sharing data and map products with stakeholders and the general public, while encountering difficult and time-consuming challenges trying to access and standardize heterogeneous data from different agencies. Therefore, institutional arrangements between key stakeholders are crucial. Institutional arrangements provide the framework for better inter-agency coordination and collaboration capabilities [47,48]. Institutional arrangements should be established beforehand as instruments to enable the development of standards, technical specifications and protocols for data collection and information sharing across all stakeholders involved in the entire disaster risk management lifecycle.

Requirement 2: Implementing a Cloud-based SDI. In emergency circumstances, decision-makers urge the generation of a common operational picture of the affected communities. Therefore, the implementation of a disaster-oriented Cloud-based SDI is necessary to enable dynamic integration and delivery of information datasets from multiple spatially-distributed sources.

Requirement 3: Linking stakeholders at the community level. In the case of emergencies, the information about unfolding events in the field changes very fast. The development of a real-time communication platform, based on standardized smartphone applications and social networks, is required to support timely interaction and participation of stakeholders in the field. This platform should make stakeholders' contributions easier and more efficient in the collection and dissemination of the most current information for early warning and facilitating emergency response at the community level. Research has shown that citizens with access to internet and standard mobile phones can contribute to rapid data measuring and mapping and to reporting data about space and events that concern them [49].

Requirement 4: Partnerships. Large-scale disastrous phenomena, such as hurricanes and earthquakes, typically obstruct limited government capabilities to supply up-to-date geospatial information and services for decision making. Therefore, partnership arrange- 
ments become crucial as a framework to develop these government geospatial capabilities, as necessary. Partnerships allow fostering the participation and trust of external stakeholders, namely, private enterprises, research institutes, universities, NGOs and local organizations, to become active contributors in the EMT operations.

Requirement 5: Capacity building. EMT operations bring together people (experts and non-experts) from a wide range of disciplines and experiences. Hence, technical trainings on data collection techniques using GPS, geospatial and data processing, metadata and information management should be a strong pillar for standardization and sharing of geospatial knowledge among team members. Continuous capacity building training programs enable each team member to support others' objectives in an effective and collaborative manner. They are also required as a first step to achieve more local community involvement to support EMT operation from the field, even when they were not used to working together before.

Our findings also highlight the necessity to regularly update these user requirement studies in order to suit the changing needs of the disaster risk management lifecycle in the SIDS context. Non-technical actions, including strengthening the organization and coordination capabilities of emergencies response agencies, involvement of local community and first responders and development of technical documentation and procedures for EMT operations, are also important.

The results of this study would lead to practitioners and regional organizations' improvement of their understanding of what needs to be prepared for an efficient EMT operation in future mapping actions for humanitarian emergencies. This new knowledge would also offer a sound foundation for the development of regional mechanisms to support multilateral cooperation and sharing of geospatial resources among decision makers and emergency response agencies in the Caribbean region and other SIDS all around the world.

The results of this study may also be useful for international agencies that are helping SIDS to enhance resilience to respond to disasters. Before embarking on their tasks of cooperation, these agencies would study the user requirements of EMT operations in the SIDS they are going to work for.

For future research, we would extend our focus to identifying important and feasible factors for enhancing SDI performance to facilitate the disaster risk management process in the SIDS context.

Author Contributions: The authors' individual contributions are specified as followed: conceptualization, G.R.M., J.C. and F.M.A.; methodology, G.R.M., L.N.G., C.V.C. and J.C.; software, G.R.M., T.J.D. and L.N.G.; formal analysis, G.R.M., C.V.C., F.M.A. and J.C.; investigation, G.R.M. and J.C.; resources, G.R.M., T.J.D. and J.C.; data curation, G.R.M., L.N.G. and C.V.C.; writing-original draft preparation, G.R.M. and J.C.; writing—review and editing, G.R.M., F.M.A., T.J.D. and J.C.; visualization, G.R.M., L.N.G. and C.V.C.; project administration, G.R.M.; funding acquisition, G.R.M., T.J.D. and J.C. All authors have read and agreed to the published version of the manuscript.

Funding: This research was funded by the Ministry of Higher Education, Science and Technology (MESCYT) of the Dominican Republic and the National Geological Survey of the Dominican Republic, under grant number FONDOCYT 2018-2019-1E3-065.

Acknowledgments: We wish to acknowledge the contribution to our research made by the InterInstitutional Geospatial Information Team (EIGEO, in Spanish), Dominican Republic; National Emergency Management Organization (NEMO) and Department of Physical Planning, Saint Lucia; and, the Disaster Manager Office at the Sint Maarten Fire Department, for their time and patience to answer our survey questions. We also want to acknowledge the comments of the four anonymous reviewers and the editor that helped us to improve this research paper. We thank the support of technical and administrative personnel at the National Geological Survey of the Dominican Republic. We also want to thank Santiago Muñoz Tapia and Claudia Acra Despradel for their encouragement and valuable insights for the development of this research.

Conflicts of Interest: The authors declare no conflict of interest. 


\section{Appendix A}

Table A1. Recommendations for anticipating EMT users' needs (Q14).

\begin{tabular}{|c|c|c|c|}
\hline Category & Dominican Republic & Saint Lucia & Sint Maarten \\
\hline $\begin{array}{c}\text { Effective } \\
\text { Communication }\end{array}$ & $\begin{array}{ll}- & \text { Link stakeholders } \\
\text { - } & \text { Use of social networks } \\
\text { - } & \text { Specific communication } \\
\text { channels } \\
\text { - } \quad \begin{array}{l}\text { Workshops to identify users' } \\
\text { needs }\end{array}\end{array}$ & $\begin{array}{l}\text { - } \quad \begin{array}{l}\text { Reduction of efforts to } \\
\text { obtain information }\end{array} \\
\text { - } \quad \text { Analysis of past events } \\
\text { and associated } \\
\text { responses }\end{array}$ & $\begin{array}{l}\text { Feedback system to } \\
\text { provide a framework on } \\
\text { which to evaluate and } \\
\text { assess }\end{array}$ \\
\hline $\begin{array}{l}\text { Automatization of } \\
\text { processes }\end{array}$ & $\begin{array}{ll}\text { - } & \text { Identification of workflow and } \\
\text { missing data sources } \\
\text { - } & \text { Stakeholders profile database } \\
\text { - } & \text { Modeling of emergencies } \\
\text { scenarios }\end{array}$ & $\begin{array}{l}\text { Tools and techniques for } \\
\text { data collection }\end{array}$ & $\begin{array}{l}\text { Drone surveys prior to } \\
\text { calamities }\end{array}$ \\
\hline Training & $\begin{array}{l}\text { - Trainings in information } \\
\text { management } \\
\text { - } \quad \text { Trainings }\end{array}$ & $\begin{array}{l}\text { - Continuous technical } \\
\text { trainings }\end{array}$ & No response \\
\hline Coordination & $\begin{array}{ll}\text { - } & \text { Logistic support and incentives } \\
\text { - } & \text { Monitoring mechanisms for } \\
\text { mapping operations }\end{array}$ & $\begin{array}{ll}- & \text { Clear directives } \\
\text { - } & \text { Provision of the right } \\
\text { resources }\end{array}$ & No response \\
\hline Standardization & $\begin{array}{ll}\text { - } & \text { Standardized information } \\
\text { gathering processes } \\
\text { - } & \text { Request form for maps output } \\
\text { - } & \text { Graphic outputs of the maps }\end{array}$ & No response & No response \\
\hline Data specification & - $\quad$ No response & $\begin{array}{l}\text { - Up-to-date geospatial } \\
\text { data } \\
\text { - } \quad \text { Sharing and storage of } \\
\text { data in a central area } \\
\text { - } \quad \text { Data analysis }\end{array}$ & No response \\
\hline
\end{tabular}

Table A2. Recommendations for EMT data generation (Q25).

\begin{tabular}{|c|c|c|c|}
\hline Category & Dominican Republic & Saint Lucia & Sint Maarten \\
\hline $\begin{array}{l}\text { Geospatial data } \\
\text { and metadata }\end{array}$ & $\begin{array}{ll}\text { - } & \text { National SDI for DRM } \\
\text { - } & \text { Accessibility to updated data } \\
\text { - } & \text { Access procedure to updated } \\
\text { data } \\
\text { - } & \text { Satellite data to monitor } \\
\text { hazards } \\
\text { - } \quad \begin{array}{l}\text { Continuous update of existing } \\
\text { datasets }\end{array}\end{array}$ & $\begin{array}{ll}\text { - } & \text { Capturing imagery after } \\
\text { events } \\
\text { - } & \text { Georeferencing data } \\
\text { - } & \text { Mandatory metadata }\end{array}$ & $\begin{array}{ll}\text { - } \quad \text { Integrated multi-actors } \\
\text { geospatial databases } \\
\text { - } \quad \text { Collection, storage and } \\
\text { exploitation of } \\
\text { geospatial data }\end{array}$ \\
\hline $\begin{array}{l}\text { Human resources } \\
\text { and capacity building }\end{array}$ & $\begin{array}{ll}\text { - } & \text { Technical personnel exclusive } \\
\text { - } & \text { Vor emergency mapping } \\
\text { - } & \text { Trainingers to collect data } \\
\text { trends } & \\
\text { - } & \text { Trained team in information } \\
\text { management }\end{array}$ & $\begin{array}{ll}\text { - } & \text { Training of staffs in } \\
\text { stakeholder agencies } \\
\text { - } & \text { Trained specialists } \\
- & \text { More trainings to } \\
\text { increase efficiency }\end{array}$ & $\begin{array}{l}\text { A GIS unit to conduct } \\
\text { the data capture, } \\
\text { analysis and } \\
\text { dissemination }\end{array}$ \\
\hline
\end{tabular}


Table A2. Cont.

\begin{tabular}{|c|c|c|c|}
\hline Category & Dominican Republic & Saint Lucia & Sint Maarten \\
\hline $\begin{array}{l}\text { Tools for data } \\
\text { collection }\end{array}$ & $\begin{array}{l}\text { - } \quad \text { Mobile Apps for capturing data } \\
\text { - } \quad \text { High precision on data } \\
\text { capturing }\end{array}$ & $\begin{array}{ll}\text { - } & \text { Tools for real-time data } \\
\text { collection from the field } \\
\text { - } \quad \begin{array}{l}\text { Provision of better } \\
\text { equipment }\end{array} \\
\text { - } \quad \text { Utilization of smart } \\
\text { phones in data gathering }\end{array}$ & No response \\
\hline Standardization & $\begin{array}{ll}\text { - } & \text { Data capturing procedures } \\
\text { - } & \text { Unified national data capturing } \\
\text { template } \\
\text { - } \quad \text { Users' experiences analysis }\end{array}$ & - $\quad$ No response & $\begin{array}{ll}\text { - } & \text { Data capture } \\
\text { methodology }\end{array}$ \\
\hline Coordination & $\begin{array}{l}\text { - Logistical support and } \\
\text { incentives } \\
\text { - Monitoring mechanisms for the } \\
\text { mapping operations }\end{array}$ & $\begin{array}{l}\text { - } \quad \text { Getting more public } \\
\text { involvement }\end{array}$ & No response \\
\hline
\end{tabular}

Table A3. Recommendations for EMT geospatial and data processing (Q30).

\begin{tabular}{|c|c|c|c|}
\hline Categories & Dominican Republic & Saint Lucia & Sint Maarten \\
\hline Distributed processing & $\begin{array}{ll}\text { - } & \text { Web services applications to reduce } \\
\text { redundancy } \\
\text { - } \quad \text { Rapid response to updated } \\
\text { information } \\
\text { - } \quad \text { Software and hardware update }\end{array}$ & - $\quad$ No response & 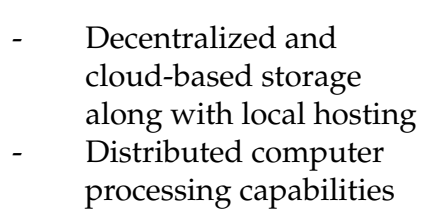 \\
\hline $\begin{array}{l}\text { Spatial data } \\
\text { infrastructure }\end{array}$ & $\begin{array}{l}\text { - } \quad \text { National SDI for disaster } \\
\text { management } \\
\text { - } \quad \text { Supported with skilled personnel } \\
\text { and the latest technologies }\end{array}$ & $\begin{array}{l}\text { Migration of GIS } \\
\text { capabilities to the } \\
\text { Cloud }\end{array}$ & No response \\
\hline Standardization & $\begin{array}{l}\text { Standardized protocol for data and } \\
\text { geospatial processing }\end{array}$ & No response & $\begin{array}{ll}\text { - } & \text { Metadata } \\
\text { - } & \text { Data format } \\
\text { Metadata to be collected } \\
\text { and saved to use } \\
\text { alongside data }\end{array}$ \\
\hline Capacity building & $\begin{array}{l}\text { - } \quad \begin{array}{l}\text { Enhance technical skills in } \\
\text { emergency management }\end{array} \\
\text { - } \quad \begin{array}{l}\text { Strengthen theoretical and technical } \\
\text { capabilities }\end{array} \\
\text { - } \quad \text { Trainings for technical staffs } \\
\text { - } \quad \text { Continuous training }\end{array}$ & $\begin{array}{l}\text { - Users' need } \\
\text { assessments for } \\
\text { anticipating future } \\
\text { events } \\
\text { Trainings }\end{array}$ & $\begin{array}{l}\text { - } \quad \text { Trainings on geospatial } \\
\text { and data processing }\end{array}$ \\
\hline
\end{tabular}


Table A4. Recommendations for EMT mapping and layout (Q33).

\begin{tabular}{|c|c|c|c|}
\hline Categories & Dominican Republic & Saint Lucia & Sint Maarten \\
\hline Standardization & $\begin{array}{ll}\text { - } & \text { Emergency symbology } \\
- & \text { Map template } \\
- & \text { Automotive processes } \\
\text { - } & \text { Geospatial information } \\
& \text { platform }\end{array}$ & No response & $\begin{array}{ll}- & \text { Map layouts } \\
- & \text { Map symbology }\end{array}$ \\
\hline Technical capabilities & $\begin{array}{l}\text { - } \quad \text { Strengthen the hardware } \\
\text { infrastructure } \\
\text { - } \quad \text { Technical trainings }\end{array}$ & $\begin{array}{ll}\text { - } & \text { Mobile apps for } \\
\text { real-time data } \\
\text { acquisition } \\
\text { - } \quad \text { Sharing of files and } \\
\text { information } \\
\text { - } \quad \text { Equipment and updated } \\
\text { software } \\
\text { - Updated software } \\
\text { licenses }\end{array}$ & $\begin{array}{ll}\text { - } & \text { Mobile GIS apps for } \\
\text { real-time data collection } \\
\text { and updating } \\
\text { - } \quad \text { Real-time operational } \\
\text { GIS data dashboard }\end{array}$ \\
\hline Geospatial information & $\begin{array}{ll}\text { - } & \text { Continuous access to base data } \\
\text { - } & \text { Real time post-disaster } \\
\text { information }\end{array}$ & $\begin{array}{ll}- & \text { Up-to-date road maps } \\
- & \text { Mapping of critical } \\
\text { infrastructures }\end{array}$ & $\begin{array}{l}\text { Accurate data as the } \\
\text { workflow progress }\end{array}$ \\
\hline $\begin{array}{l}\text { Organizational } \\
\text { capabilities }\end{array}$ & - Involvement of local authorities & $\begin{array}{l}\text { Planning and } \\
\text { preparedness for } \\
\text { mitigation purpose }\end{array}$ & $\begin{array}{l}\text { - An organizational } \\
\text { structure }\end{array}$ \\
\hline
\end{tabular}

Table A5. Recommendations for EMT products sharing and continuous updates (Q37).

\begin{tabular}{|c|c|c|c|}
\hline Categories & Dominican Republic & Saint Lucia & Sint Maarten \\
\hline Spatial data infrastructure & $\begin{array}{ll}- & \text { National SDI for DRM } \\
- & \text { Open data approach } \\
\text { - } & \text { Easy access }\end{array}$ & $\begin{array}{ll}\text { - } & \text { Accessible to the public } \\
\text { - } & \text { Dissemination of spatial } \\
\text { data to all stakeholders }\end{array}$ & $\begin{array}{ll}\text { - } & \text { Local level SDI } \\
\text { - } & \text { Scalable computer } \\
\text { - } & \text { servers } \\
& \text { Increased storage } \\
\text { capacity } & \text { Reliable ICT tools }\end{array}$ \\
\hline $\begin{array}{l}\text { Participatory mapping and } \\
\text { capacity building }\end{array}$ & $\begin{array}{l}\text { - Knowledge reutilization } \\
\text { for developing required } \\
\text { tools } \\
\text { - Local users involvement } \\
\text { to provide accurate and } \\
\text { relevant information }\end{array}$ & Continuous training & No response \\
\hline Standardization & No response & 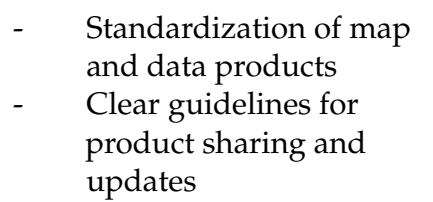 & - No response \\
\hline
\end{tabular}

\section{References}

1. UNISDR. Sendai Framework for Disaster Risk Reduction 2015-2030; United Nations Office for Disaster Risk Reduction (UNISDR): Geneva, Switzerland, 2015.

2. CRED EM-DAT. The International Disaster Database. Centre for Research on the Epidemiology of Disasters (CRED). 2020. Available online: http:/ / www.emdat.be/ (accessed on 1 June 2020).

3. OCHA-UN. Impact of Hurricanes Irma and Maria Conference Supporting Document; Office for the Coordination of Humanitarian Affairs Assessment Capacities Project United Nations Development Programme: New York, NY, USA, 2018.

4. Yates, D.; Paquette, S. Emergency knowledge management and social media technologies: A case study of the 2010 Haitian earthquake. Int. J. Inf. Manag. 2011, 31, 6-13. [CrossRef] 
5. Diehl, S.; van der Heide, J. Geo-information breaks through sector think. In Geo-Information for Disaster Management; Springer: Berlin/Heidelberg, Germany, 2019; pp. 85-108.

6. Haworth, B.; Whittaker, J.; Bruce, E. Assessing the application and value of participatory mapping for community bushfire preparation. Appl. Geogr. 2016, 76, 115-127. [CrossRef]

7. Helmholz, P.; Zlatanova, S.; Barton, J.; Aleksandrov, M. Geoinformation for Disaster Management 2020 (GI4DM2020): PREFACE. ISPRS Ann. Photogramm. Remote Sens. Spatial Inf. Sci. 2020, VI-3, 1-2.

8. Fernández, T.D.; Crompvoets, J. Evaluating Spatial Data Infrastructures in the Caribbean for sustainable development. In Proceedings of the GSDI-10 Conference, Small Island Perspectives on Global Challenges: The Role of Spatial Data in Supporting a Sustainable Future, St. Augustine, Trinidad and Tobago, 29 February 2008; p. 20.

9. Kimura, R.; Munenari, I.; Keiko, T.; Takashi, F.; Haruo, H. Clarifying the Function of the Emergency Mapping Team in order to Allocate the Limited Resources in the Time of 2011 Great East Japan Earthquake. In Proceedings of the TIEMS (The International Emergency Management Society), Tokyo, Japan, 22-23 May 2012; pp. 72-78.

10. Wolbers, J.; Boersma, K. The common operational picture as collective sensemaking. J. Contingencies Crisis Manag. 2013, 21, 186-199. [CrossRef]

11. Kevany, M. GIS in the World Trade Center response: 10 years after. ISPRS Int. Arch. Photogramm. Remote Sen. Spatial Inf. Sci. 2011, XXXVIII, 137-142. [CrossRef]

12. Michel, G.R.; Tapia, S.M.; Aybar, F.M.; Javier, V.G.; Crompvoets, J. Identifying Users' Requirements for Emergency Mapping Team Operations in the Dominican Republic. ISPRS Int. J. Geo-Inf. 2020, 9, 165. [CrossRef]

13. Keiko, T.; Hayashi, H. Geospatial Information Improves the Decision-Making Process during the Disaster Response: The Experience of the Emergency Mapping Team in the 2011 off the Pacific Coast of Tohoku Earthquake Takashi. In Proceedings of the 15th World Conference on Earthquake Engineering, Lisbon, Portugal, 24-28 September 2012.

14. Menold, J.; Weizler, L.; Liu, L.; Bilén, S.G.; Miller, S. Identifying end-user requirements for communication systems in disadvantaged environments. In Proceedings of the 2015 IEEE Global Humanitarian Technology Conference, Seattle, WA, USA, 8-11 October 2015; pp. 284-291.

15. Leitinger, S.H.; Scheidl, C.; Kollarits, S.; Hübl, J. User Requirements for a Mobile Disaster Documentation System. In GeoInformation for Disaster Management; van Oosterom, P., Zlatanova, S., Fendel, E.M., Eds.; Springer: Berlin/Heidelberg, Germany, 2005; pp. 305-310.

16. Neuvel, J.M.M.; Scholten, H.J.; van den Brink, A. From Spatial Data to Synchronised Actions: The Network-centric Organisation of Spatial Decision Support for Risk and Emergency Management. Appl. Spat. Anal. Policy 2012, 5, 51-72. [CrossRef]

17. Ajmar, A.; Boccardo, P.; Disabato, F.; Tonolo, F.G. Rapid Mapping: Geomatics role and research opportunities. Rendiconti Lincei. Scienze Fisiche Naturali 2015, 26, 63-73. [CrossRef]

18. Michel, G.R.; Syu, H.S.; Hong, J. A Spatial Data Infrastructure Perspective to Facilitate Emergency Mapping Team Operations. In Proceedings of the 34th Asian Conference on Remote Sensing 2013, ACRS 2013, Bali, Indonesia, 20-24 October 2013; Volume 5, pp. $4120-4127$.

19. Courage, C.; Baxter, K. Understanding your Users: A Practical Guide to User Requirements Methods, Tools, and Techniques; Gulf Professional Publishing: Houston, TX, USA, 2005.

20. Soares, D.S.; Cioquetta, M.; Souza, D. Analysis of techniques for documenting user requirements. In Proceedings of the Computational Science and Its Applications-ICCSA 2012, Salvador de Bahia, Brazil, 18-21 June 2012; Volume 7336, pp. 16-28.

21. Snoeren, G.; Zlatanova, S.; Crompvoets, J.; Scholten, H. Spatial Data Infrastructure for emergency management: The view of the users. In Proceedings of the 3rd GiDM, Toronto, ON, Canada, 22-25 July 2007; pp. 1-12.

22. UNFCCC. Vulnerability and Adaptation to Climate Change in Small Island Developing States; United Nations Framework Convention on Climate Change: New York, NY, USA, 2007; p. 38.

23. UN-OHRLLS. Small Island Developing States in Numbers; UN Office of the High Representative for the Least Developed Countries, Landlocked Developing Countries and Small Island Developing States: New York, NY, USA, 2015.

24. Schmid, J.P. CaribbeanDEVTrends. The Caribbean Economic Outlook in Three Graphs. 2019. Available online: https://blogs. iadb.org/caribbean-dev-trends/en/the-caribbean-economic-outlook-in-three-graphs/ (accessed on 10 June 2020).

25. World Bank. Disaster Risk Management in Latin America and the Caribbean Region: GFDRR Country Notes; World Bank: Washington, DC, USA, 2012.

26. National Bureau of Statistic. Tu Municipio en Cifras. IX Censo Nacional de Población y Vivienda 2010. 2019. Available online: https: / / www.one.gob.do/provinciales-y-municipales/tu-municipio-en-cifras / (accessed on 10 June 2020).

27. WMO. Atlas of Mortality and Economic Losses from Weather, Climate and Water Extremes (1970-2012); United Nations Office for Disaster Risk Reduction (UNISDR): Geneva, Switzerland, 2014.

28. National Geological Survey. Estudio de la Amenaza Sísmica y Vulnerabilidad Física del Gran Santo Domingo. Santo Domingo, Dominican Republic. 2015. Available online: http://sgn.gob.do/index.php/servicios/noticias/item/consultoria-especialista-ennorma-sismica-2 (accessed on 10 June 2020).

29. PAHO. Saint Lucia. Health in the Americas. 2015. Available online: https://www.paho.org/salud-en-las-americas-2017/?p=4211 (accessed on 11 June 2020). 
30. UN-OHRLLS. About the Small Island Developing States. UN Office of the High Representative for the Least Developed Countries, Landlocked Developing Countries and Small Island Developing States. 2017. Available online: http://unohrlls.org/about-sids/ (accessed on 10 October 2020).

31. GFDRR. Saint Lucia. 2020. Available online: https:/ /www.gfdrr.org/en/saint-lucia (accessed on 11 June 2020).

32. VNG International. Enhanced Resilience to Respond to Disasters. Recovery Project Sint Maarten; VNG International: The Hague, The Netherlands, 2018.

33. VROMI. About Ministry of Public Housing, Spatial Planning, Environment and Infrastructure. 2020. Available online: http: / / www.sintmaartengov.org/government/VROMI/Pages/About.aspx (accessed on 11 June 2020).

34. Yin, R.K. Case Study Research: Design and Methods; SAGE Publications: Thousand Oaks, CA, USA, 2009 ; Volume 5.

35. Maguire, M.; Bevan, N. User requirements analysis: A review of supporting methods. In Proceedings of the IFIP 17th World Computer Congress, Montréal, QC, Canada, 25-30 August 2002; pp. 133-148.

36. Eide, A.W.; Haugstveit, I.M.; Halvorsrud, R.; Skjetne, J.H.; Stiso, M. Key challenges in multi-agency collaboration during large-scale emergency management. In Proceedings of the SINTEF Digital/Software and Service Innovation, Pisa, Italy, 13 November 2012; Volume 953.

37. Waring, S.; Humann, M.; Dawson, N. Facilitators and barriers to effective information sharing during international disaster response. J. Emerg. Manag. 2019, 17, 469-486. [PubMed]

38. Dusse, F.; Júnior, P.S.; Alves, A.T.; Novais, R.; Vieira, V.; Mendonça, M. Information visualization for emergency management: A systematic mapping study. Expert Syst. Appl. 2016, 45, 424-437. [CrossRef]

39. McDougall, K. An Assessment of the Contribution of Volunteered Geographic Information during Recent Natural Disasters. In Spatially Enabling Government, Industry and Citizens: Research and Development Perspectives; Rajabifardb, A., Colleman, D., Eds.; GSDI Association Press: Needham, MA, USA, 2012; pp. 201-2014.

40. Carley, K.M.; Malik, M.; Landwehr, P.M.; Pfeffer, J.; Kowalchuck, M. Crowd sourcing disaster management: The complex nature of Twitter usage in Padang Indonesia. Saf. Sci. 2016, 90, 48-61. [CrossRef]

41. Genovese, E.; Stéphane, R. Potential of VGI as a Resource for SDIs in the North/South Context. Geomatica 2010, 64, 439-450.

42. Vratonjić, M.; Wittmann, H. Using and Optimising GIS in an Emergency Response; European Emergency Number Association: Brussels, Belgium, 2015; pp. 13-14.

43. UN-GGIM. Future Trends in Geospatial Information Management: The Five to Ten Year Vision, 3rd ed.; UN-GGIM: New York, NY, USA, 2020.

44. Bharosa, N.; Lee, J.; Janssen, M. Challenges and obstacles in sharing and coordinating information during multi-agency disaster response: Propositions from field exercises. Inf. Syst. Front. 2010, 12, 49-65. [CrossRef]

45. Boccardo, P. New perspectives in emergency mapping. Eur. J. Remote Sens. 2013, 46, 571-582. [CrossRef]

46. Comfort, L.K.; Kapucu, N. Inter-organizational coordination in extreme events: The World Trade Center attacks, September 11, 2001. Nat. Hazards 2006, 39, 309-327. [CrossRef]

47. Mcdougall, K.; Rajabifard, A.; Williamson, I. A mixed-method approach for evaluating spatial data sharing partnerships for spatial data infrastructure development. Res. Theory Adv. Spat. Data Infrastruct. Concepts 2007, 5, 55-73.

48. Crompvoets, J.; Bregt, A.; Rajabifard, A.; Williamson, I. Assessing the worldwide developments of national spatial data clearinghouses. Int. J. Geogr. Inf. Sci. 2004, 18, 665-689. [CrossRef]

49. Georgiadou, Y.; Budhathoki, N.R.; Nedovic-Budic, Z. An Exploration of SDI and Volunteered Geographic Information in Africa. In Spatial Data Infrastructures in Context, 1st ed.; CRC Press: Boca Raton, FL, USA, 2011; p. 18. 